International Journal of Advanced Mathematical Sciences, $8(1)(2020) 1-4$
International Journal of Advanced Mathematical Sciences
SPC
Website $:$ www.sciencepubco.com/index.php/IJAMS
Research paper

\title{
Further Geometric Properties of a Subclass of Univalent Functions
}

\author{
Ezekiel A. Oyekan \\ Department of Mathematical Sciences, Olusegun Agagu University of Science and Technology \\ (OAUSTECH), P.M.B. 353, Okitipupa, Ondo State, Nigeria \\ shalomfa@yahoo.com
}

\begin{abstract}
This present paper aims to investigate further, certain characterization properties for a subclass of univalent function defined by a generalized differential operator. In particular, necessary and sufficient conditions for the function $f(z)$ to belong to the subclass $\varphi_{\mu}^{n}(\beta, \alpha)$ is established. Additionally, we provide the $\boldsymbol{\delta}$-neighborhood properties for the function $\left[f(z)=z-\sum_{k=2}^{\infty} a_{k} z^{k}, a_{k} \geq 0\right] \in \varphi_{\mu}^{n}(\beta, \alpha)$ by making use of the necessary and sufficient conditions. The results obtained are new geometric properties for the subclass $\varphi_{\mu}^{n}(\beta, \alpha)$.
\end{abstract}

Keywords: Analytic Functions; Univalent Functions; Differential Operator; Neighborhood.

\section{Introduction}

Let $A$ denotes the class of functions $f(z)$ which are analytic in the unit disk $U=\{z \in C:|z|<1\}$. Also, let the class of all functions in $A$ which are univalent in $\mathrm{U}$ be denoted by the symbol $\mathrm{S}$ and of the form

$f(z)=z+\sum_{k=2}^{\infty} a_{n} z^{n}$

It is well known that any function $\mathrm{f} \in \mathrm{S}$ has the Taylor series expansion of the form (1), for details (see Duren [1] and Pommerenke [2]). The form (1) is the normalized form of functions $f(z) \in A$ for which the normalization condition is given by

$\mathrm{f}(0)=0$ and $\mathrm{f}^{\prime}(0)=1$.

Thus,

$S=\left\{f \in A: f(0)=f^{\prime}(0)-1=0\right\}$.

Some well-known properties of functions in the class S can be found elsewhere (see [1], [3] and [4]), while some special classes of univalent functions have also been investigated by various authors (see [5], [6], [7], [8], [9], [10] and [11]).

Furthermore, we denote by $T$ the subclass of A consisting of functions $f(z) \in A$ which are analytic and univalent in $U$ and of the form

$f(z)=z-\sum_{k=2}^{\infty} a_{k} z^{k}, a_{k} \geq 0$

The class $\varphi_{\mu}^{\mathrm{n}}(\beta, \alpha)$, a subclass of univalent functions was introduced and studied by Oyekan [10]. For this class, the author established both convolution and inclusion properties for the class. Other subsequent work on the class can be found in Oyekan and Kehinde [12].

Definition 1: [10] A function $f(z) \in A$ is in the class $\varphi_{\mu}^{n}(\beta, \alpha)$ of provided $D_{\mu, p}^{n}[f(z)]^{\prime} \in p(\alpha)$. That is, if

$\operatorname{Re}\left[\mathrm{D}_{\mu, \mathrm{p}}^{\mathrm{n}}(\mathrm{f}(\mathrm{z}))^{\prime}\right]>\alpha, \mathrm{z} \in \mathrm{U}$, for $0 \leq \alpha<1,1 \leq \mu \leq \beta, \mathrm{n} \in \mathbb{N}_{0}=\mathbb{N} \cup\{0\}$.

We note that $\mathrm{p}(\alpha) \in \mathrm{P}$ which is the class of the Caratheodory functions.

In the sequel, we shall state and prove our new results for the class $\varphi_{\mu}^{\mathrm{n}}(\beta, \alpha)$. These new results presented in section 2 , are motivated by the results in Opoola [9]. 


\section{Results and discussion}

\subsection{Necessary and sufficient conditions}

Theorem 2.1: Let $f(z)=z+\sum_{k=2}^{\infty} a_{k} z^{k} \in A$.

If

$\mathrm{z}+\sum_{\mathrm{k}=2}^{\infty} \mathrm{k}[\mathrm{k}(1+\beta-\mu)]^{\mathrm{n}}\left|\mathrm{a}_{\mathrm{k}}\right|<1-\alpha$,

then $\mathrm{f}(\mathrm{z}) \in \varphi_{\mu}^{\mathrm{n}}(\beta, \alpha)$.

Proof: It suffices to show that

$\left|\left(D_{\mu, \beta}^{\mathrm{n}} \mathrm{f}(\mathrm{z})\right)^{\prime}-1\right|<1-\alpha, 0 \leq \alpha<1$

Now,

$\left|\left(D_{\mu, \beta}^{\mathrm{n}} \mathrm{f}(\mathrm{z})\right)^{\prime}-1\right|=\left|1+\sum_{\mathrm{k}=2}^{\infty} \mathrm{k}\left[\mathrm{k}(1+\beta-\mu)^{\mathrm{n}}\right] \mathrm{a}_{\mathrm{k}} \mathrm{z}^{\mathrm{k}-1}-1\right|$

$=\left|\sum_{\mathrm{k}=2}^{\infty} \mathrm{k}\left[\mathrm{k}(1+\beta-\mu)^{\mathrm{n}}\right] \mathrm{a}_{\mathrm{k}} \mathrm{z}^{\mathrm{k}-1}\right|=\sum_{\mathrm{k}=2}^{\infty} \mathrm{k}\left[\mathrm{k}(1+\beta-\mu)^{\mathrm{n}}\right] \mathrm{a}_{\mathrm{k}}|\mathrm{z}|^{\mathrm{k}-1}$

$\leq \sum_{\mathrm{k}=2}^{\infty} \mathrm{k}\left[\mathrm{k}(1+\beta-\mu)^{\mathrm{n}}\right]\left|\mathrm{a}_{\mathrm{k}}\right|$.

Thus, by the condition of the theorem, we have that

$\left|\left(D_{\mu, \beta}^{\mathrm{n}} \mathrm{f}(\mathrm{z})\right)^{\prime}-1\right|<1-\alpha$

Hence, the proof is complete.

Theorem 2.2: A function $f(z)$ of the form given by (2) belongs to the class $\varphi_{\mu}^{n}(\beta, \alpha)$ if and only if

$\sum_{\mathrm{k}=2}^{\infty} \mathrm{k}\left[\mathrm{k}(1+\beta-\mu)^{\mathrm{n}}\right] \mathrm{a}_{\mathrm{k}}<1-\alpha, 0 \leq \alpha<1$.

Proof: Let $\mathrm{f}(\mathrm{z})=\mathrm{z}-\sum_{\mathrm{k}=2}^{\infty} \mathrm{a}_{\mathrm{k}} \mathrm{z}^{\mathrm{k}} \in \varphi_{\mu}^{\mathrm{n}}(\beta, \alpha), \mathrm{a}_{\mathrm{k}} \geq 0$.

Then

$\operatorname{Re}\left(D_{\mu, \beta}^{\mathrm{n}} \mathrm{f}(\mathrm{z})\right)^{\prime}>\alpha$

Which implies

$\left|\left(D_{\mu, \beta}^{\mathrm{n}} \mathrm{f}(\mathrm{z})\right)^{\prime}-1\right|<1-\alpha$

$\left|\left(D_{\mu, \beta}^{\mathrm{n}} \mathrm{f}(\mathrm{z})\right)^{\prime}-1\right|=\left|1+\sum_{\mathrm{k}=2}^{\infty} \mathrm{k}\left[\mathrm{k}(1+\beta-\mu)^{\mathrm{n}}\right] \mathrm{a}_{\mathrm{k}} \mathrm{z}^{\mathrm{k}-1}-1\right|$

$\operatorname{Re}\left(\sum_{\mathrm{k}=2}^{\infty} \mathrm{k}\left[\mathrm{k}(1+\beta-\mu)^{\mathrm{n}}\right] \mathrm{a}_{\mathrm{k}} \mathrm{z}^{\mathrm{k}-1}\right)<1-\alpha$.

Taking values of $\mathrm{z}$ on real axis and letting $\mathrm{z} \rightarrow-1$ through real values we have From (5) that

$\sum_{\mathrm{k}=2}^{\infty} \mathrm{k}\left[\mathrm{k}(1+\beta-\mu)^{\mathrm{n}}\right] \mathrm{a}_{\mathrm{k}}<1-\alpha$.

Conversely,

$\left|\sum_{\mathrm{k}=2}^{\infty} \mathrm{k}\left[\mathrm{k}(1+\beta-\mu)^{\mathrm{n}}\right] \mathrm{a}_{\mathrm{k}} \mathrm{z}^{\mathrm{k}-1}\right| \leq \sum_{\mathrm{k}=2}^{\infty} \mathrm{k}\left[\mathrm{k}(1+\beta-\mu)^{\mathrm{n}}\right]\left|\mathrm{a}_{\mathrm{k}}\right|$

$=\sum_{\mathrm{k}=2}^{\infty} \mathrm{k}\left[\mathrm{k}(1+\beta-\mu)^{\mathrm{n}}\right] \mathrm{a}_{\mathrm{k}}$.

Hence, by the condition of the theorem we have that

$\left|\left(D_{\mu, \beta}^{n} f(z)\right)^{\prime}-1\right|<1-\alpha$.

Consequently 
$\operatorname{Re}\left(D_{\mu, \beta}^{n} f(z)\right)^{\prime}>\alpha$,

And hence

$f(z)=z-\sum_{k=2}^{\infty} a_{k} z^{k} \in \varphi_{\mu}^{n}(\beta, \alpha)$.

\subsection{Neighborhoods for $\varphi_{\mu}^{n}(\beta, \alpha)$}

Let $f(z) \in \varphi_{\mu}^{n}(\beta, \alpha)$ and $\delta \geq 0$, we define the $\delta$ - neighborhood of $f(z)$ as

$N_{\delta}(f):=\left\{g \in A: g(z)=z+\sum_{k=2}^{\infty} a_{k} z^{k} \in \varphi_{\mu}^{n}(\beta, \alpha)\right.$ and $\left.\sum_{k=2}^{\infty} b_{k}\left|a_{k}-b_{k}\right| \leq \delta\right\}$

In particular, for the identity function $\mathrm{e}(\mathrm{z})=\mathrm{z}$, we immediately have

$\mathrm{N}_{\delta}(\mathrm{e}):=\left\{\mathrm{g} \in \mathrm{A}: \mathrm{g}(\mathrm{z})=\mathrm{z}+\sum_{\mathrm{k}=2}^{\infty} \mathrm{a}_{\mathrm{k}} \mathrm{z}^{\mathrm{k}} \in \varphi_{\mu}^{\mathrm{n}}(\beta, \alpha)\right.$ and $\left.\sum_{\mathrm{k}=2}^{\infty} \mathrm{k}\left|\mathrm{b}_{\mathrm{k}}\right| \leq \delta\right\}$.

The concept of neighborhood of analytic functions above was sequel to the works of Goodman [13] and Ruscheweyh [14].

The main goal in this subsection is to investigate the $\delta$ - neighborhood of $\mathrm{f}(\mathrm{z}) \in \varphi_{\mu}^{\mathrm{n}}(\beta, \alpha)$ with negative coefficients.

Theorem 2.3: If

$$
\delta=\frac{1-\alpha}{[2(1+\beta-\mu)]^{n}}
$$

Then $\varphi_{\mu}^{\mathrm{n}}(\beta, \alpha) \subset \mathrm{N} \delta(\mathrm{e})$.

Proof: Let $\mathrm{f}(\mathrm{z}) \in \varphi_{\mu}^{\mathrm{n}}(\beta, \alpha)$.

Then from Theorem 2.1, we have that

$\sum_{\mathrm{k}=2}^{\infty} \mathrm{k}[\mathrm{k}(1+\beta-\mu)]^{\mathrm{n}}|\mathrm{ak}|<1-\alpha$,

Which implies that

$[2(1+\beta-\alpha)]^{\mathrm{n}} \sum_{\mathrm{k}=2}^{\infty} \mathrm{k}\left|\mathrm{a}_{\mathrm{k}}\right|<1-\alpha$.

That is,

$\sum_{\mathrm{k}=2}^{\infty} \mathrm{k}\left|\mathrm{a}_{\mathrm{k}}\right|<\frac{1-\alpha}{[2(1+\beta-\mu)]^{\mathrm{n}}}$,

Which by (7) gives that $f(z) \in N_{\delta}(e)$.

Hence,

$\varphi_{\mu}^{\mathrm{n}}(\beta, \alpha) \subset \mathrm{N}_{\delta}(\mathrm{e})$.

\section{Conclusion}

For the class $\varphi_{\mu}^{\mathrm{n}}(\beta, \alpha)$, various results have been obtained and can be found in $[10,12]$. Whereas, the results presented in this present work are new geometric properties for the class.

\section{References}

[1] Duren P.L., Univalent functions, A Series of Comprehensive studies in Mathematics by Springer-Verlag, New York Berlin-Heidelberg-Tokyo, 259 (1983).

[2] Pommerenke C, Univalent functions with a chapter on quadratic differentials by Gerr Jesen, vandenhoeck and Ruprecht in Gottingen, Germany (1975)

[3] Bieberbach L. Über die Koeffizienten derjenigen Potenzreihen, welcheeine Schlichting Abbildung des Einheitskreises vermitteln, Preuss, Akad. Wiss., Phys. Math. K1. (1916) 138:940-955.

[4] Goodman A.W., Univalent functions, Mariner Publ. comp., Tampa, Florida, (1983).

[5] Mocanu P.T, Bulboacă T, Sãlãgean GŞ. Teoria Geometrică a Funcţiilor Analitice, Casa Cărtii de Ştiinţă, Cluj-Napoca, (1999), 77-81.

[6] Robertson MS. "On the theory of univalent functions". Ann. Math. (1936) 37:374-408. https://doi.org/10.2307/1968451.

[7] Sãlãgean G. Ş. Subclasses of univalent functions. Complex Analysis 5th Romanian-Finish Seminar, Part I (Bucharest, 1981), Lecture Notes Math.1031. Springer-Verlag. 1981 362-372. https://doi.org/10.1007/BFb0066543.

[8] Raducanu, D. "On a subclass of univalent functions defined by a generalized differential operator". Math. Reports 13, 63 no. 2 (2011), 197-203

[9] Opoola O. T., "On a subclass of univalent function defined by a Generalized Differential Operator", International journal of mathematical Analysis, 11 no. 18 (2017), 869-876. https://doi.org/10.12988/ijma.2017.7232.

[10] Oyekan, E. A. "Some properties for a subclass of univalent functions", Asian journal of mathematics and computer research, 20 no. 1 (2017), $32-$ 37. http://www.ikprress.org/index.php/AJOMCOR/article/view/981

[11] Ruscheweyh S., New criteria for univalent functions, Proc. Amer. Math. Soc., 49(1975), 109-115. https://doi.org/10.1090/S0002-9939-19750367176-1. 
[12] Oyekan, E. A. and Kehinde R. Subordination results on certain new subclasses of analytic functions, "Confluence Journal of Pure and Applied Sciences" (CJPAS), 2 no. 2(2018), 116-123.

[13] Goodman, A. W. Univalent functions and nonanalytic curves, Proc. Amer. Math. Soc., 8(1957) 598-601. https://doi.org/10.1090/S0002-9939-19570086879-9.

[14] Ruscheweyh, S. Neighborhoods of univalent functions, Proc. Amer. Math. Soc., 81 (1981) 521-527. https://doi.org/10.1090/S0002-9939-1981$\underline{0601721-6 .}$ 